\title{
Diversity Analysis of Arabidopsis thaliana (L.) Heynh Ecotypes for Glucosinolates in Shoots and Seeds
}

\author{
Dilip R. Panthee', Dean A. Kopsell ${ }^{2}$, and Carl E. Sams ${ }^{3,4}$ \\ Plant Sciences Department, The University of Tennessee, Room 252 Ellington \\ Plant Science Building, Knoxville, TN 37996-4561 \\ Additional index words. Brassica, germplasm
}

\begin{abstract}
Glucosinolates (GS) are important secondary plant metabolites present in several plant species, including Arabidopsis thaliana (L.) Heynh. Although genotypic differences among a limited number of samples from a limited geographical range have been reported, there have been few studies exploring the variation from a wider genetic base. The objective of this study was to explore the genetic variation for GS in $A$. thaliana collected throughout the world. We screened 58 A. thaliana ecotypes collected from the geographic area of lat. $15^{\circ} \mathrm{N}$ to lat. $59^{\circ} \mathrm{N}$ and long. $137^{\circ} \mathrm{E}$ to long. $123^{\circ} \mathrm{W}$. Elevation in these areas ranged from sea level to over $480 \mathrm{~m}$. We believe that this study has covered a large geographical region and captured most of the available genetic variation in $A$. thaliana for GS. There was no geographical trend in $A$. thaliana shoot or seed tissue for GS concentration. Total shoot GS ranged from 1.1 to $52.8 \mu \mathrm{mol} \cdot \mathrm{g}^{-1}$ dry weight (DW), averaging $9.3 \mu \mathrm{mol} \cdot \mathrm{g}^{-1} \mathrm{DW}$ among all ecotypes. Total seed GS ranged from 1.6 to 41.8 $\mu \mathrm{mol} \cdot \mathrm{g}^{-1} \mathrm{DW}$ with an average of $16.8 \mu \mathrm{mol} \cdot \mathrm{g}^{-1} \mathrm{DW}$ among all ecotypes. Low and high GS-accumulating $A$. thaliana ecotypes identified in this study may provide a basis for further genetic analysis for GS metabolism. Information provided may also prove useful for improving concentrations of nutritionally beneficial GS in vegetable Brassicas.
\end{abstract}

Glucosinolates (GS) are important sulfurcontaining secondary metabolites present in a number of plant species, including Arabidopsis thaliana (L.) Heynh (Halkier and Du, 1997). More than 100 types of GS have been reported in plant species with 23 different types present in A. thaliana. The family Brassicaceae, of which $A$. thaliana is a member, represents a diverse group of plant species commercially important in many parts of the world. The plants produce condiment mustard; leafy, stored, processed, and picked vegetables; seed oils for margarine, salad oils, cooking oils, and industrial uses; animal fodders; and green manure crops (Williams and Hill, 1986). Isothiocyanate compounds produced in these plants through hydrolysis of GS by the enzyme myrosinase convey their unique flavor and volatile attributes, and they can also act as antioxidants and anticancer agents when consumed in the diet. The presence is GS in $A$. thaliana offers the opportunity to study the biochemical pathways of these compounds in a widely used model plant system. Information gained from A. thaliana may shed new

Received for publication 9 Feb. 2011. Accepted for publication 3 May 2011.

This research was funded through financial support of the Tennessee Agriculture Research Experiment. ${ }^{1}$ Assistant Professor. Current address: Department of Horticultural Science, North Carolina State University, Mountain Horticultural Crops Research and Extension Center, Mills River, NC 28759.

${ }^{2}$ Associate Professor.

${ }^{3}$ Professor.

${ }^{4}$ To whom reprint requests should be addressed; e-mail carlsams@utk.edu. light on impact of GS and their hydrolysis products in chronic disease prevention.

Glucosinolates demonstrate anticancer properties through the production of detoxification enzymes formed during hydrolysis such as quinine reductase, glutathione-S-transferase, and glucuronosyl transferase (Fahey et al., 1997; Holst and Williamson, 2004). Sulforaphane, an important GS derivative, possesses the most potent anticancer properties (Zhang et al., 1992). Sulforaphane is derived from 4-methylsulfinylbutyl GS, found in abundance in broccoli (Brassica oleracea var. Italica) heads, and functions through disruption of mitotic cell division processes, hence suppressing tumor growth. Realizing the potential use of GS in cancer treatment, several studies have evaluated broccoli accession and found significant differences for aliphatic GS (possessing specific anticancer properties) indicating that there is a potential to improve broccoli for desirable GS (Brown et al., 2002; Jeffery et al., 2003). Such genetic variation has also been reported in A. thaliana (Kliebenstein et al., 2001) as well as other vegetable Brassicas (Castro et al., 2004; Schonhof et al., 2004). However, in all cases, the genetic base and geographical range of collection of material has been narrow. Therefore, our research objectives were to acquire $A$. thaliana germplasm from as wide a geographic region as possible and then screen both leaf and seed tissues for GS concentrations.

\section{Materials and Methods}

Plant materials. We acquired $A$. thaliana seeds of 58 different ecotypes from the
Arabidopsis Resource Center at The Ohio State University (Columbus, $\mathrm{OH}$ ). The center maintains collections from 25 countries, detailed information on ecotypes, country of origin, altitude, and latitude and longitude of the original sample collection site (Table 1). Seed from all ecotypes were planted in superfine germinating mix (BM; Berger, Saint-Modeste, Quebec, Canada) in 12.5-cm diameter plastic pots arranged in a completely randomized design with three replications and grown in a controlled environment (Environmental Growth Chambers, Chagrin Falls, $\mathrm{OH}$ ) at a constant air temperature of $20{ }^{\circ} \mathrm{C}$ under a 16-h photoperiod. Photosynthetically active radiation at the canopy height was 400 to $425 \mu \mathrm{mol} \cdot \mathrm{m}^{-2} \cdot \mathrm{s}^{-1}$ (LI-188B; LI-COR, Inc., Lincoln, NE). After 2 weeks, seedlings were thinned to three plants per pot and fertigated with quarter-strength Arabidopsis nutrient solution (Arteca and Arteca, 2000) on a weekly basis. Shoots were harvested just before anthesis and triple-rinsed with deionized water to remove all possible soil and other materials, frozen in liquid nitrogen, and stored at $-80^{\circ} \mathrm{C}$ until high-performance liquid chromatography (HPLC) analysis.

For seed GS evaluation, the same $58 \mathrm{~A}$. thaliana ecotypes were germinated and grown as previously described. To bulk seed volumes for analysis, plants were randomly crossed within each ecotype and allowed to set seeds. Seeds were harvested along with whole plants, placed in a paper bag, and air-dried at room temperature for $7 \mathrm{~d}$ before they were cleaned for GS extraction.

Sample preparation. Both shoot and seed samples were freeze-dried at $-40{ }^{\circ} \mathrm{C}$ for $48 \mathrm{~h}$ to minimize possible myrosinase hydrolysis during grinding. An aluminum bead was added to samples to facilitate grinding by vortexing in the sample tubes at 3000 rpm for $30 \mathrm{~s}$ conducted three consecutive times.

Glucosinolate high-performance liquid chromatography analysis. Glucosinolate extraction and analysis were performed as described by Charron et al. (2001). Briefly, $0.2 \mathrm{~g}$ of freeze-dried tissue was combined with $1 \mathrm{~mL}$ benzyl glucosinolate solution $(1 \mathrm{~mm})$ as an internal standard, $2.0 \mathrm{~mL} \mathrm{MeOH}$, and $0.1 \mathrm{~mL}$ barium-lead acetate $(0.6 \mathrm{M})$ and centrifuged at $2000 g_{\mathrm{n}}$ for $10 \mathrm{~min}$. A $0.5-\mathrm{mL}$ aliquot of supernatant was then added to a $1-\mathrm{mL}$ column containing $0.3 \mathrm{~mL}$ DEAE Sephadex A-25 (Sigma-Aldrich, St. Louis, MO). The sample was desulfated by the procedure of Raney and McGregor (1990). Desulfoglucosinolates was eluted with $900 \mu \mathrm{L}$ of water and collected into 2-mL vials. Extracted desulfoglucosinolates were separated with an Agilent 1100 HPLC unit (Agilent Technologies, Palo Alto, CA) with a photodiode array detector using a reversephase $250 \mathrm{~mm} \times 4.6 \mathrm{~mm}$ i.d., $5-\mu \mathrm{m}$ Luna $\mathrm{C}_{18}$ column (Phenomenex, Inc., Torrance, CA) at a wavelength of $230 \mathrm{~nm}$. The column temperature was set at $40^{\circ} \mathrm{C}$ with a flow rate of $1 \mathrm{~mL} \cdot \mathrm{min}^{-1}$. The gradient elution parameters were $100 \%$ water for $1 \mathrm{~min}$ followed by a 15 min linear gradient to $75 \%$ water: $25 \%$ acetonitrile. Solvent levels were then held constant 
Breeding, Cultivars, Rootstocks, and Germplasm Resources

Table 1. List of Arabidopsis thaliana ecotypes accession, country of origin, altitude (m), and latitude $\left({ }^{\circ}\right)$, and longitude $\left(^{\circ}\right)$ of the site of original sample collection.

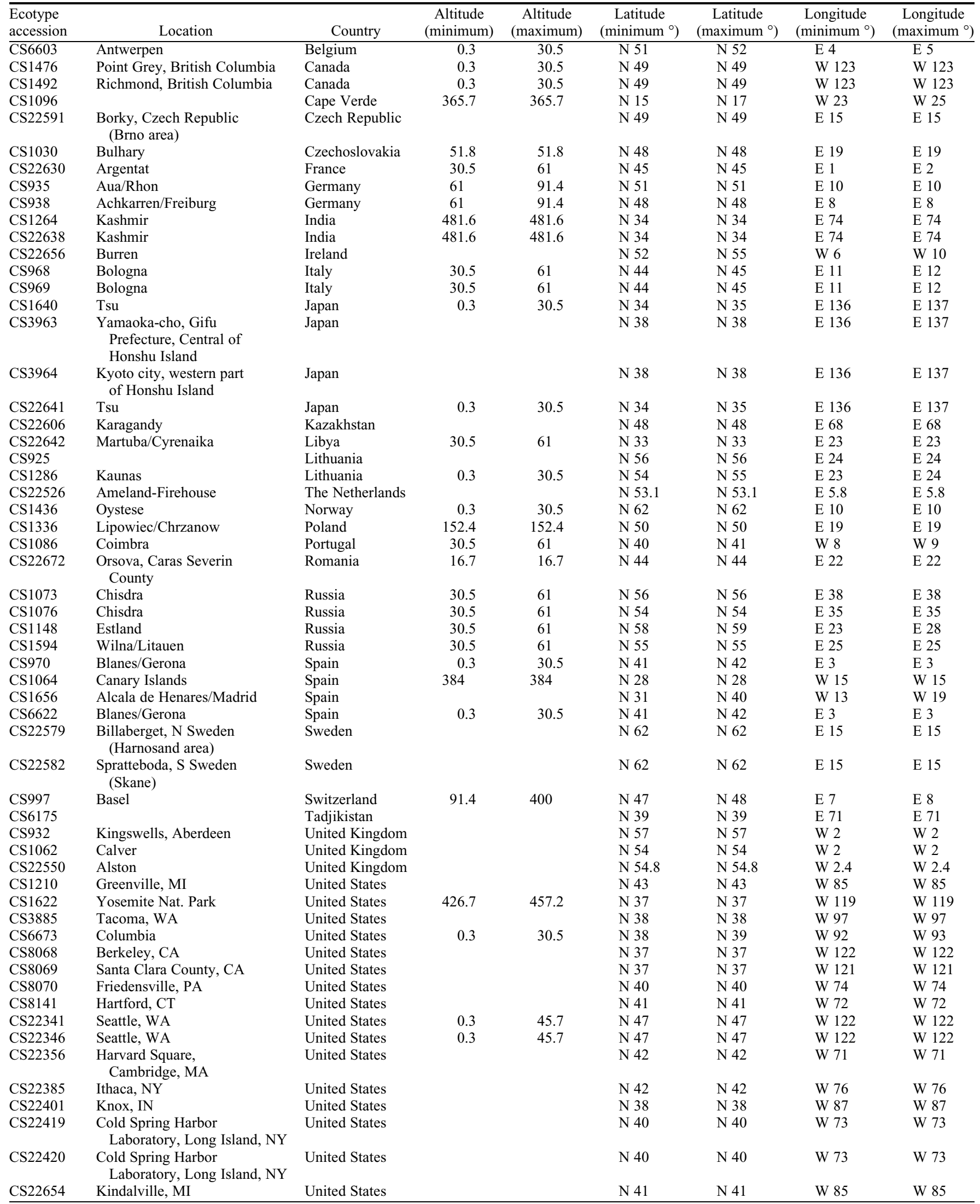

for $5 \mathrm{~min}$ and returned to $100 \%$ water for the final 5 min. Desulfoglucosinolates were identified by comparison with authentic standards and previously reported results
(Charron et al., 2001). Desulfonated forms of glucoiberin (3-methylsulfinylpropyl GS), glucobrassicin (indol-3-ylmethyl GS), gluconapin (3-butenyl GS), 4-methoxyglucobrassicin (4-methoxyindol-3-ylmethyl GS), neoglucobrassicin, 1-methoxyindol-3-ylmethyl GS, progoitrin (2-hydroxybut-3-enyl GS), and sinigrin (2-propenyl GS) were provided by Sandro 


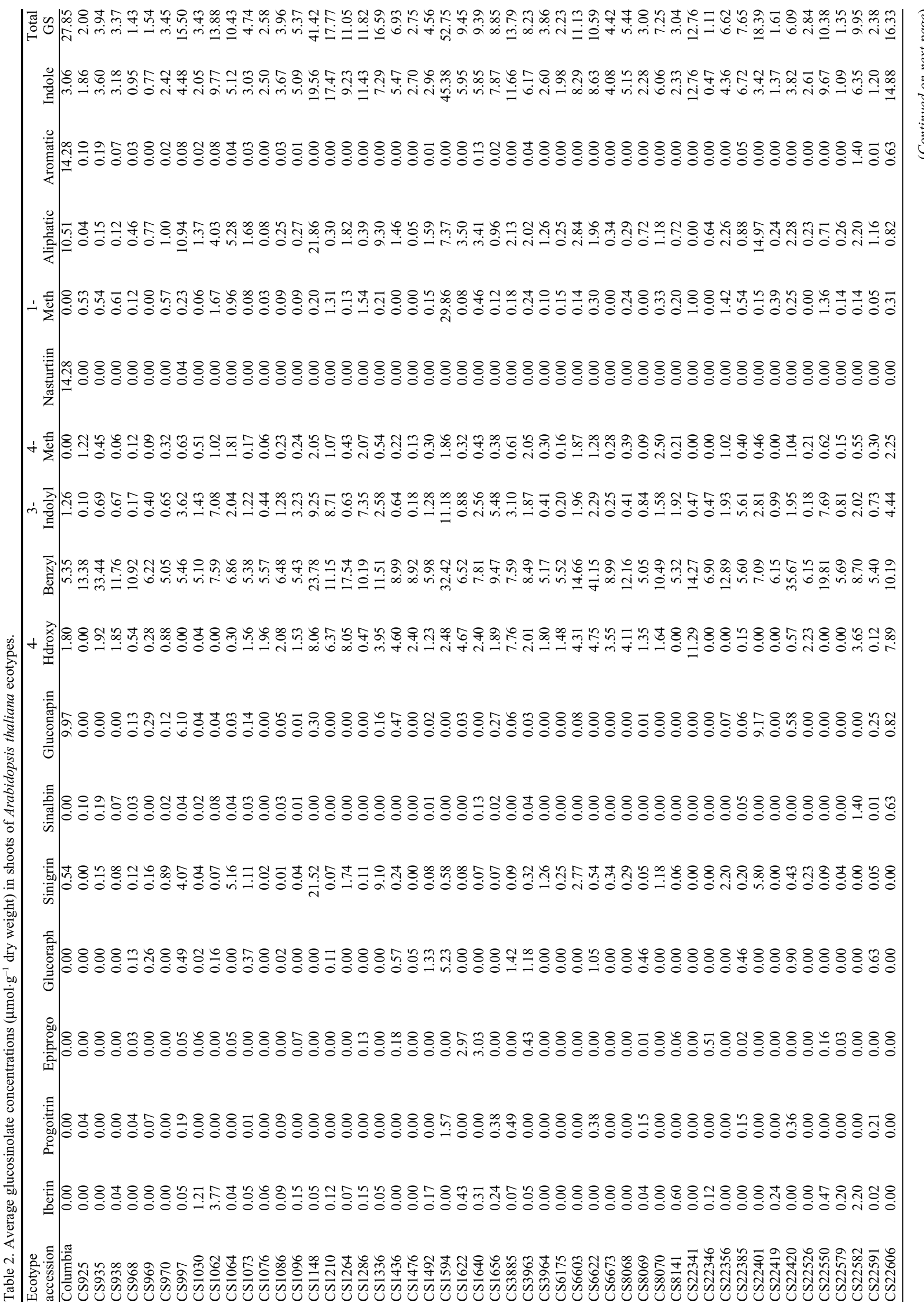




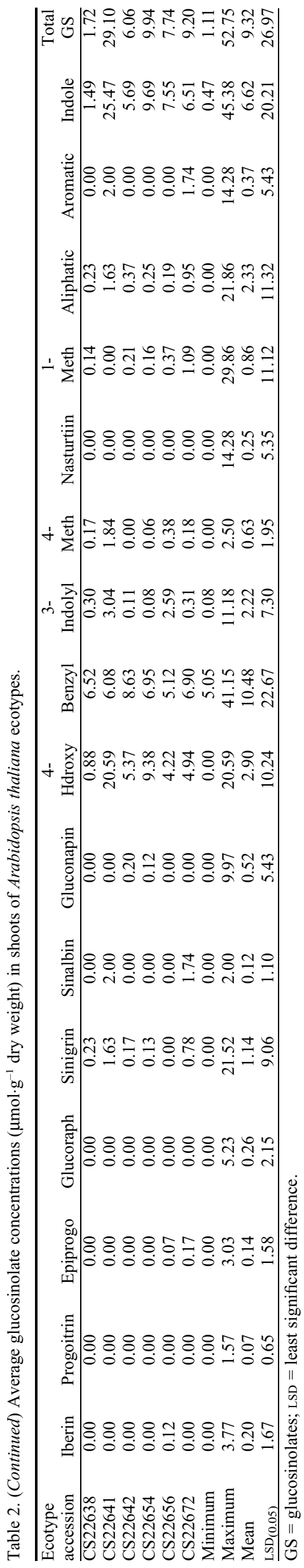

Palmieri of the Instituto Sperimentale Industriali (Bologna, Italy). Gluconasturtiin (2-phenylethyl GS) was purchased from LKT Laboratories Inc. (St. Paul, MN). Response factors used were from quantification based on the International Organization for Standardization (Method 9167-1).

Statistical analysis. Data were subjected to one-way analysis of variance and Pearson correlation analysis was performed with SAS software (Version 9.1; SAS Institute, Cary, $\mathrm{NC})$.

\section{Results and Discussion}

We received ecotypes collected from a wide range of geographic locations, evaluated them under controlled conditions, and present findings that establish genetic variations for GS present in the A. thaliana germplasm. Although many studies have assessed the genetic diversity for GS in vegetable Brassicas (Brown et al., 2002; Jeffery et al., 2003; Kushad et al., 1999; Schonhof et al., 2004), data are currently lacking on GS variations among available A. thaliana ecotypes.

Glucosinolates in A. thaliana shoots. The A. thaliana ecotypes differed $(P<0.05)$ for individual and total GS levels measured in shoot tissues (Table 2). Average total GS concentration among the ecotypes was 9.32 $\mu \mathrm{mol} \cdot \mathrm{g}^{-1} \mathrm{DW}$, ranging from 1.11 to 52.75 $\mu \mathrm{mol} \cdot \mathrm{g}^{-1}$ DW (Table 2 ). The relatively high SD (9.52) for this range of observation may indicate a large variation among the ecotypes for total GS concentration. Despite this large variation, there were only four ecotypes with greater than $25 \mu \mathrm{mol} \cdot \mathrm{g}^{-1} \mathrm{DW}$ for total shoot
GS in this study with the majority of ecotypes (39) having less than $10 \mu \mathrm{mol} \cdot \mathrm{g}^{-1} \mathrm{DW}$ total shoot GS (Table 2). The ecotypes also varied significantly for shoot tissue aliphatic, aromatic, and indole GS. Although all ecotypes contained at least trace amounts of indole GS, some of those were devoid of aliphatic and aromatic GS in shoot tissue (Table 2). Indole GS contributed at least $11 \%$ in some of the ecotypes to as high as $100 \%$ to the total GS concentration. However, aromatic and aliphatic GS contributed to total GS as high as $38 \%$ and $81 \%$, respectively. Data presented provide a basis for genetic variation for individual and total GS in shoot tissues among available $A$. thaliana ecotypes. Geographical mapping of ecotypes on the basis of total GS did not show any particular pattern of distribution at a global level (Fig. 1).

Glucosinolates in A. thaliana seeds. There were also differences among $A$. thaliana ecotypes for total GS in seeds. Average total seed GS concentration $\left(16.75 \mu \mathrm{mol} \cdot \mathrm{g}^{-1} \mathrm{DW}\right)$ was higher than in shoots, but the range for seed GS (1.63 to $41.79 \mu \mathrm{mol} \cdot \mathrm{g}^{-1} \mathrm{DW}$ ) was narrower (Table 3). There were seven ecotypes with greater than $25 \mu \mathrm{mol} \cdot \mathrm{g}^{-1} \mathrm{DW}$ of total seed GS (Table 3). This indicated that there are not many lines with a high concentration of seed GS. The majority of ecotypes had less than $20 \mu \mathrm{mol} \cdot \mathrm{g}^{-1}$ DW total seed GS. Similar to the shoot tissue, indole-GS was the major component of total GS, contributing as high as $99 \%$ in some of the ecotypes. Contributions by aliphatic and aromatic components to total seed GS were $39 \%$ and $8 \%$, respectively. Eucin GS was found in seeds of at least 33 ecotypes of A. thaliana, but it was not detected in shoots

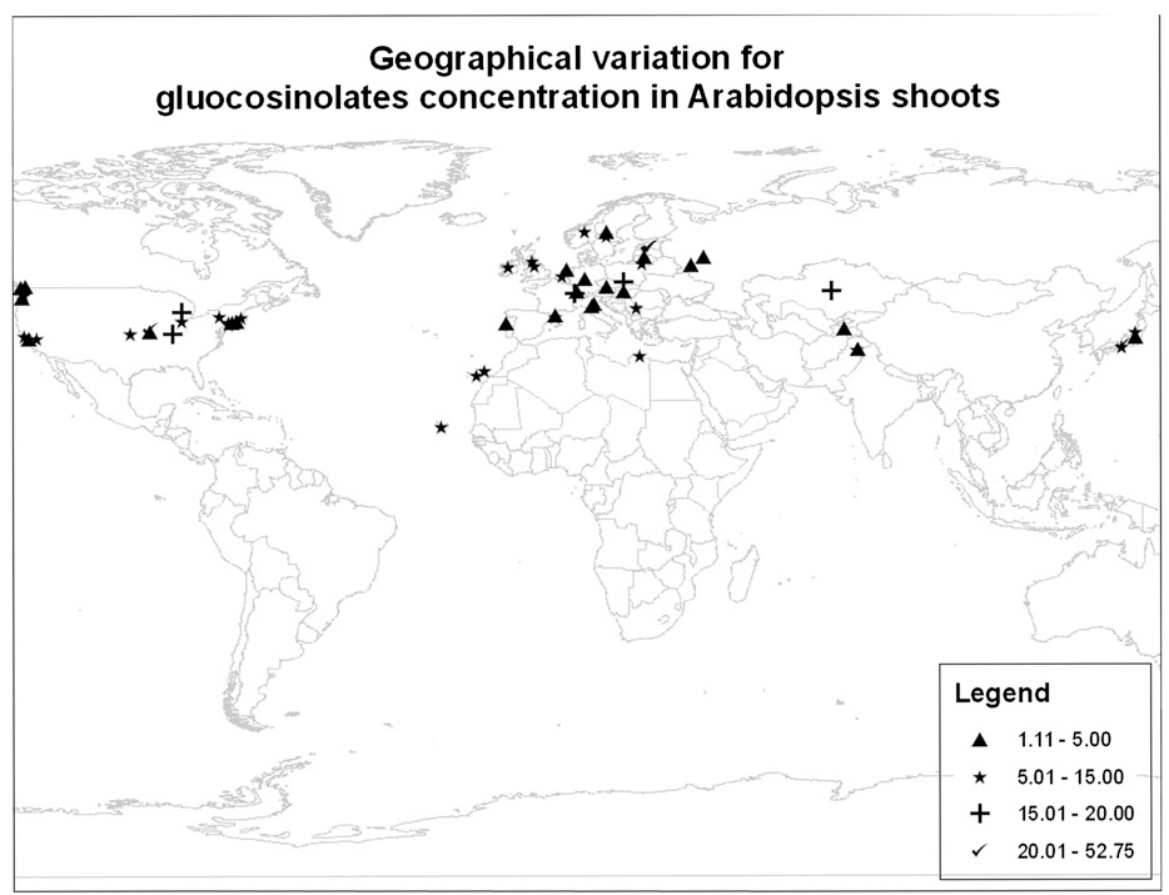

Fig. 1. Geographical distribution pattern of total glucosinolate concentration $\left(\mu \mathrm{mol} \cdot \mathrm{g}^{-1}\right.$ dry weight) in Arabidopsis thaliana shoot tissues. 


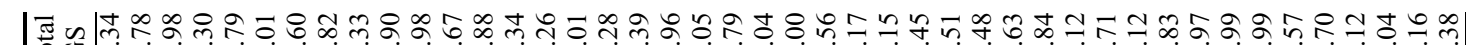

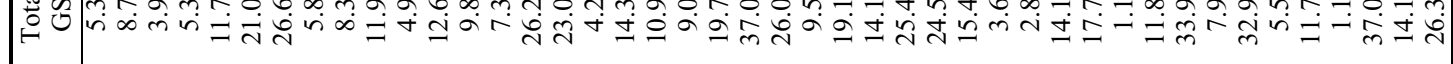

号

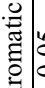

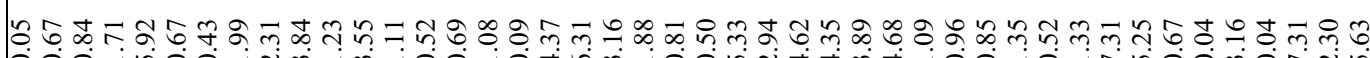

安

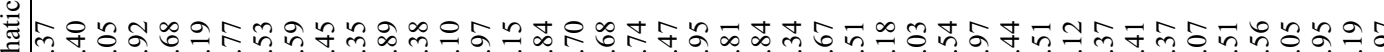
:

- ₹

$\because 8$

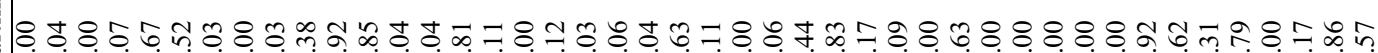

孶

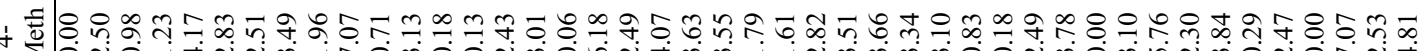
+ $\sum^{2}$ (1)

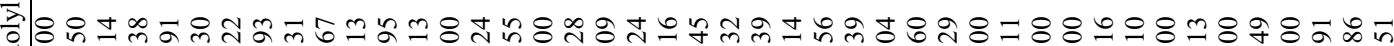

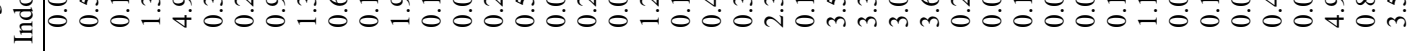

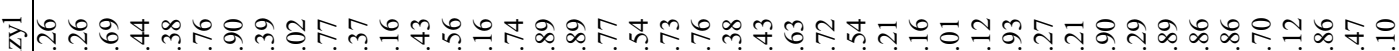
刉

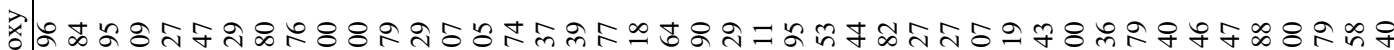

핸.

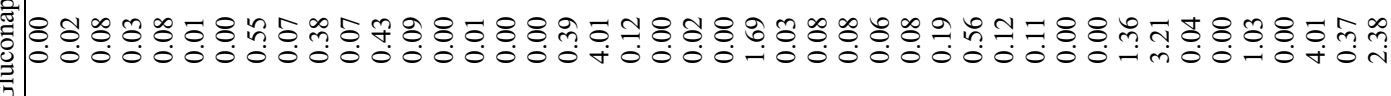

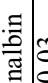

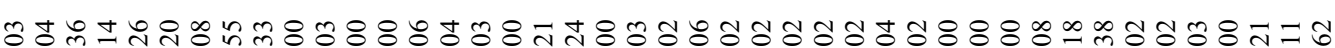
औ

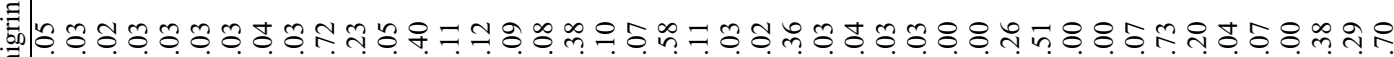

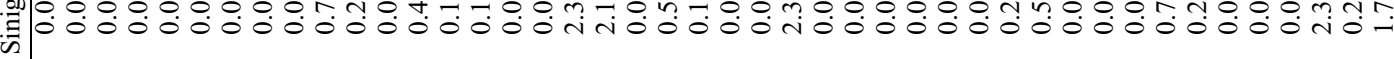

芴

:

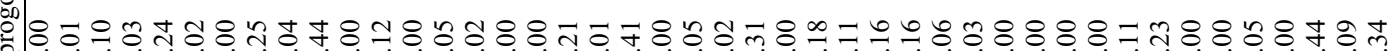
워

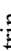

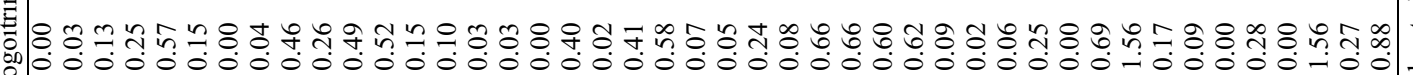
는

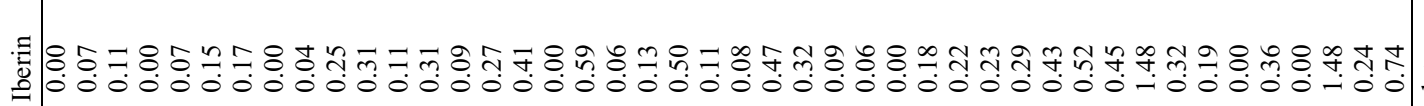

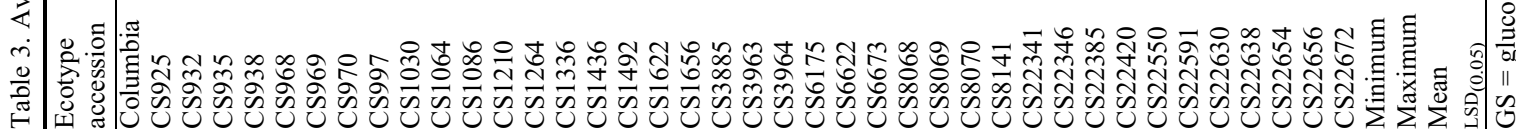


(Tables 2 and 3). The maximum concentration of eucin found in the seeds was $4.91 \mu \mathrm{mol} \cdot \mathrm{g}^{-1}$ DW. This indicates that some of the GS may possibly be synthesized at a later stage of plant development.

In the case of seed GS, there was no specific pattern of geographical distribution in terms of total GS (Fig. 2). It is possible that soil type, fertility status of the soil as well as climatic conditions of the location from where samples were collected may have an influence on the levels of GS in seeds of $A$. thaliana. Every attempt was made to minimize any possible environmental impacts in the current evaluation; however, the variation in seed GS observed in this study may not entirely be from genetic contributions.

Correlations among glucosinolates for shoot and seed tissues in A. thaliana. There were strong positive correlations for total shoot GS with the individual shoot GS of gluconapin, nasturtiin, aliphatic, total aromatic, and total indole-GS (Table 4). Similar trends in GS were observed with the seed tissues (Table 4). This has advantages and disadvantages in any improvement efforts of a plant species for a trait of interest, because it provides an opportunity to improve a trait independently. Although indole-GS had a positive correlation with total GS in seeds, aliphatic and aromatic GS were weakly correlated. Other strongly correlated GS with total GS in seeds were 3-indolyl and 4-meth, whereas others showed a mixed pattern (Table 4).

Contrary to the present findings, higher concentrations of GS are usually present in seed tissues of $A$. thaliana (Brown et al., 2003). Although the overall average total GS concentration was higher in A. thaliana seeds

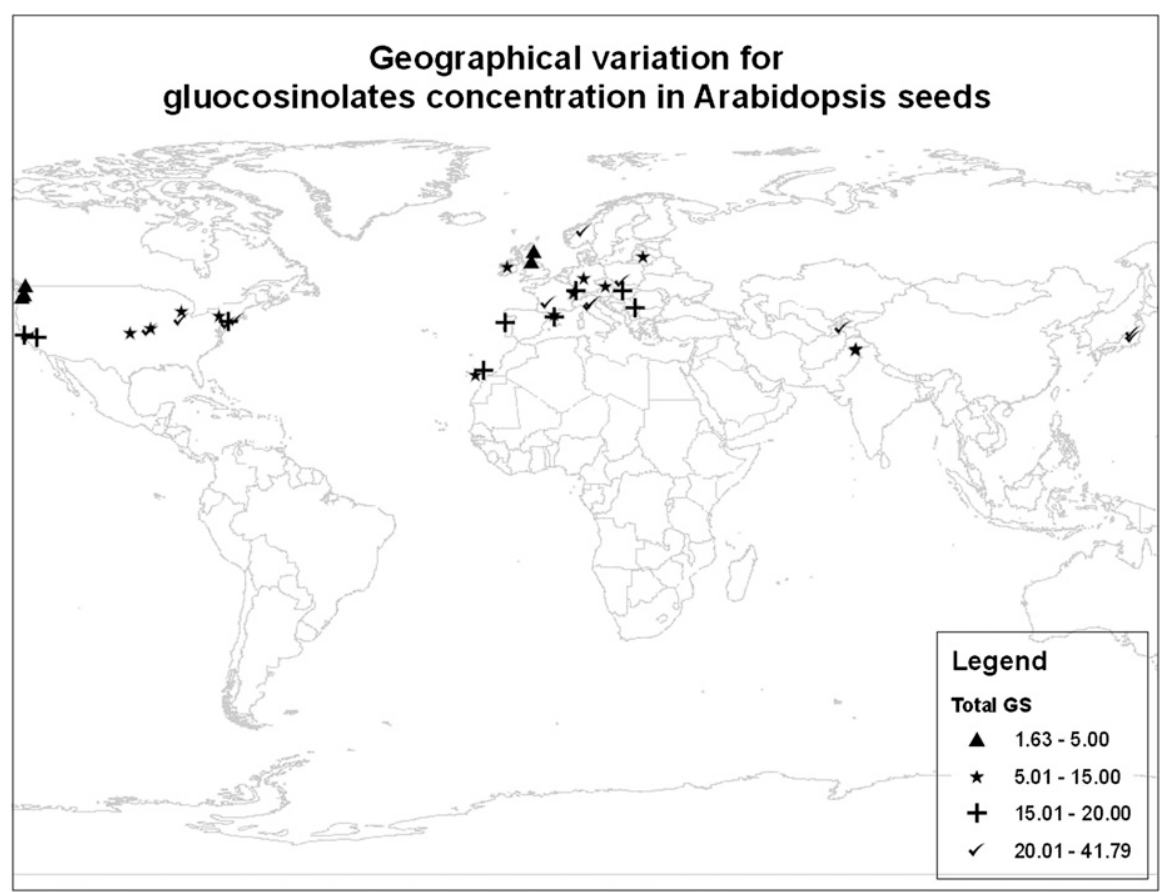

Fig. 2. Geographical distribution pattern of total glucosinolate concentration $\left(\mu \mathrm{mol} \cdot \mathrm{g}^{-1}\right.$ dry weight) in Arabidopsis thaliana seed tissues. in the present study, the highest concentration of total GS for any ecotype was found in the shoot tissue. It is possible that the conversion of one type of GS into another during changes in plant developmental stages differed among the $A$. thaliana ecotypes. Brown et al. (2003) reported concentrations of GS from inflorescence and silique tissues in $A$. thaliana plants to range from 23 to 30 $\mu \mathrm{mol} \cdot \mathrm{g}^{-1} \mathrm{DW}$, and the average GS shoot tissue concentration among $A$. thaliana ecotypes in the current evaluation of 27.85 $\mu \mathrm{mol} \cdot \mathrm{g}^{-1} \mathrm{DW}$ is in agreement. This also indicates the precision of the analyses between two independent studies.

Brown et al. (2003) found that aliphatic GS contributed more than $80 \%$ of the total GS in A. thaliana leaf tissues. Contributions of this level were only in a few $A$. thaliana ecotypes in the present study with the majority of ecotypes showing less aliphatic GS percentages of total GS. Indole GS was the major contributor to total GS among the ecotypes in the present study. However, the declining trend of contribution of aliphatic GS to the total GS observed by Brown et al. (2003) is in agreement with the present study when we compare shoots and seeds. Brown et al. (2003) also reported additional GS in seeds that were not present in the shoots at vegetative growth stages for $A$. thaliana. Kliebenstein et al. (2001) identified a single locus $(G S-A O P)$, which accounted for over $60 \%$ of the variation for shoot tissue aliphatic GS among 39 A. thaliana ecotypes. However, the authors found that the same locus exhibited no significant association with aliphatic GS in seed tissues. Such conclusions would indicate

that accumulations of GS in shoot and seed

$$
\text { not }
$$
process of evolution of the $A$. thaliana genome genetic changes controlling GS biosynthesis may have taken place independently at various locations throughout the worldwide geographic distribution of ecotypes.

More than 100 types of GS have been identified in A. thaliana. We report only 19 GS to be present in the shoot tissues and 20 GS present in the seed tissues of the A. thaliana ecotypes evaluated in the present study. Evaluations were conducted at the seed stage and in shoots just before anthesis in the present study, indicating the number of GS may vary according to different growth stages. Furthermore, negative or no correlations between different GS from seeds and shoots indicated that GS metabolism may be independent from one growth stage to another. Correlation observations made in the present study were also in agreement with previous observations (Kliebenstein et al., 2001). Low and high GScontaining ecotypes identified in shoots and seeds from this study may provide a basis for further investigations aimed at identifying genes associated with GS biosynthesis. These ecotypes can also be used for other research such as microarray analysis and genetic transformation of $A$. thaliana to manipulating the GS levels. 


\section{Literature Cited}

Arteca, R.N. and J.M. Arteca. 2000. A novel method for growing Arabidopsis thaliana plants hydroponically. Physiol. Plant. 108:188-193.

Brown, A.F., G.G. Yousef, E.H. Jeffery, B.P Klein, M.A. Wallig, M.M. Kushad, and J.A Juvik. 2002. Glucosinolate profiles in broccoli: Variation in levels and implications in breeding for cancer chemoprotection. J. Amer. Soc. Hort. Sci. 127:807-813.

Brown, P.D., J.G. Tokuhisa, M. Reichelt, and J. Gershenzon. 2003. Variation of glucosinolate accumulation among different organs and developmental stages of Arabidopsis thaliana. Phytochemistry 62:471-481.

Castro, A., A. Aires, E. Rosa, E. Bloem, I. Stulen, and L.J. De Kok. 2004. Distribution of glucosinolates in Brassica oleracea cultivars. PhytonAnnales Rei Botanicae 44:133-143.

Charron, C.S., D.A. Kopsell, W.M. Randle, and C.E. Sams. 2001. Sodium selenate fertilisation increases selenium accumulation and decreases glucosinolate concentration in rapid-cycling Brassica oleracea. J. Sci. Food Agr. 81:962966.

Charron, C.S., A.M. Saxton, and C.E. Sams. 2005. Relationship of climate and genotype to seasonal variation in the glucosinolate-myrosinase system. II. Myrosinase activity in ten cultivars of Brassica oleracea grown in fall and spring seasons. J. Sci. Food Agr. 85:682-690.

Fahey, J.W., Y.S. Zhang, and P. Talalay. 1997. Broccoli sprouts: An exceptionally rich source of inducers of enzymes that protect against chemical carcinogens. Proc. Natl. Acad. Sci. USA 94:10367-10372.

Halkier, B.A. and L.C. Du. 1997. The biosynthesis of glucosinolates. Trends Plant Sci. 2:425431.

Holst, B. and G. Williamson. 2004. A critical review of the bioavailability of glucosinolates and related compounds. Nat. Prod. Rep. 21: 425-447.

Jeffery, E.H., A.F. Brown, A.C. Kurilich, A.S Keck, N. Matusheski, B.P. Klein, and J.A. Juvik. 2003. Variation in content of bioactive components in broccoli. J. Food Compost. Anal. 16:323-330.

Kliebenstein, D.J., J. Kroymann, P. Brown, A Figuth, D. Pedersen, J. Gershenzon, and T. Mitchell Olds. 2001. Genetic control of natural variation in Arabidopsis glucosinolate accumulation. Plant Physiol. 126:811-825.

Kushad, M.M., A.F. Brown, A.C. Kurilich, J.A. Juvik, B.P. Klein, M.A. Wallig, and E.H. Jeffery. 1999 Variation of glucosinolates in vegetable crops of Brassica oleracea. J. Agr. Food Chem. 47: $1541-1548$

Raney, J.P. and D.I. McGregor. 1990. Determination of glucosinolate content by gas liquid chromatography of trimethylsilyl derivatives of desulfated glucosinolates. Proc. Oil Crops Network, Shanghai, China, 21-23, Apr. 1990.

Schonhof, I., A. Krumbein, and B. Bruckner. 2004 Genotypic effects on glucosinolates and sensory properties of broccoli and cauliflower. NahrungFood 48:25-33.

Williams, P.H. and C.B. Hill. 1986. Rapid cycling populations of Brassica. Sci. 232:1385-1389.

Zhang, Y.S., P. Talalay, C.G. Cho, and G.H. Posner. 1992. A major inducer of anticarcinogenic protective enzymes from broccoli-Isolation and elucidation of structure. Proc. Natl. Acad. Sci. USA 89:2399-2403. 